\title{
Neuroaxial anesthesia for gynecological surgeries: meta-analysis
}

\author{
Luan Souza Cajaiba' \\ Mayara Rezende Reis ${ }^{2}$ \\ Marina Viegas Moura Rezende Ribeiro ${ }^{3}$ \\ Fabiano Timbó Barbosa ${ }^{4}$
}

1. Medical student at Brazilian university Universidade Federal de Alagoas, UFAL

2. Medical student at Brazilian university Universidade Federal de Alagoas, UFAL

3. Master degree holder in health sciences

4. Faculty professor of medicine at Brazilian university Universidade Federal de Alagoas. Doctor degree holder in health sciences

KEYWORDS: Mortality. Anesthesia, general. Anesthesia, epidural. Anesthesia, spinal. Review.

\section{INTRODUCTION}

Major surgical procedures increase the risk of fatal events. For this reason, influence of anesthetic techniques employed is discussed. ${ }^{1}$ Anesthesia has the potential to induce physiological changes that may influence patients' morbidity and mortality. Despite this, several studies have shown that there is a tendency of decrease in mortality rates related to anesthesia. $^{2}$

Neuraxial anesthesia (NA) refers to the use of local anesthetics in the vicinity of the spinal cord in order to abolish the perception of painful stimuli. ${ }^{3}$ General anesthesia (GA) refers to the use of drugs that lead to loss of consciousness and, consequently, to the abolition of the perception of painful stimuli. ${ }^{3}$ Anesthetic techniques have not undergone major changes in recent decades, except for the appearance of new drugs as well as new therapy strategies for pain and control of postoperative nausea and vomiting. ${ }^{4}$

A systematic review attempts to gather all the empirical evidence that fits into prespecified inclusion criteria to answer a specific research question. ${ }^{5}$
Due to the lack of articles proving effectiveness and safety of neuraxial anesthesia in general in major gynecologic surgeries, this systematic review of randomized clinical trials aims to determine effectiveness and safety of NA compared to GA for major gynecologic surgeries, assisting anesthesiologists in choosing the technique to be used.

\section{METHODS}

The study has not been submitted to the Research Ethics Committee (REC) because it is research with analysis of secondary data that are available in databases of medical literature as well as in libraries of laboratories and scientific journeys and events involving the topic of this research.

\section{Protocol}

A protocol has been developed for the present research and is available with the author, in case there is need of analysis. This systematic review is in agreement with the items proposed in The Preferred

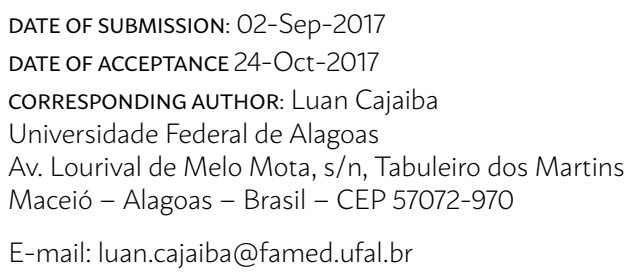

mayararesende@gmail.com dra.marinaribeiro@gmail.com fabianotimbo@yahoo.com.br 
Reporting Items for Systematic Reviews and Meta-analyses (PRISMA) statement ${ }^{6}$. The journal, the institution where the study was conducted and the researchers have not influenced the results obtained.

\section{Inclusion criteria}

Types of participants: Female patients, older than 18 years, who have undergone some major gynecologic surgery.

Type of study: Randomized controlled trials have been used.

Types of intervention: The intervention group was submitted to NA. The control group was submitted to GA.

\section{Exclusion criteria}

Duplicate articles, articles with incomplete data and those not obtained in full were excluded.

\section{Identification of studies}

Search strategies were developed to identify original articles from randomized clinical trials related to the topic in the databases selected for this research. Electronic bases selected were: Embase (Excerpta Medica dataBASE), available on: <http://aplicacao. periodicos.saude.gov.br/> (1974 a agosto de 2017); LILACS (Literatura Latino-Americana e do Caribe em Ciências da Saúde), available on: <http://regional.bvsalud.org/php/index.php> (1982 to August 2017); MEDLINE $^{\circledR}$ (Medical Literature Analysis and Retrieval System Online), via free search engine PubMed (1966 to August 2017) and freely accessible web search engine Google Scholar (August 2017 2017).

A search strategy was created for the PubMed database. The strategies of all databases were based on the PubMed search strategy. The search strategy on Embase was: "'general anesthesia'/exp OR 'spinal anesthesia'/exp OR 'epidural anesthesia'/exp AND rand" AND 'gynecologic surgical procedures' /exp". The search strategy used on Lilacs was "general anesthesia OR spinal anesthesia OR epidural anesthesia OR gynecologic surgery OR controlled trial." The search strategy used on Google Scholar was "'general anesthesia', 'spinal anesthesia', 'epidural anesthesia', 'gynecologic surgery', 'randomized controlled trial' OR 'controlled clinical trial”'. There were no restrictions on language, date and format of the document. The search strategy used in PubMed is as follows:

((“general anaesthesia”[All Fields] OR "anesthesia, general”[MeSH Terms] OR ("anesthesia”[All
Fields] AND "general"[All Fields]) OR "general anesthesia"[All Fields] OR ("general"[All Fields] AND”anesthesia"[All Fields])) OR (neuraxial[All Fields] AND ("anaesthesia"[All Fields] OR "anesthesia"[MeSH Terms] OR "anesthesia"[All Fields])) AND ("gynaecological surgery"[All Fields] OR "gynecologic surgical procedures"[MeSH Terms] OR ("gynecologic"[All Fields] AND "surgical”[All Fields] AND "procedures"[All Fields]) OR "gynecologic surgical procedures"[All Fields] OR ("gynecological”[All Fields] AND "surgery"[All Fields]) OR "gynecological surgery"[All Fields]) AND ("randomized controlled trial"[Publication Type] OR "randomized controlled trials as topic"[MeSH Terms] OR "randomized controlled trial"[All Fields] OR "randomised controlled trial”[All Fields])).

\section{Selection of studies}

Titles, abstracts or both, identified through the search strategy in each electronic database, were independently analyzed by two researchers (CAJAIBA, L. S.; REIS, M. R.). Articles that met the eligibility criteria were obtained in full for reading. Contact through e-mail correspondence was tried with some authors to clarify doubts about the study variables, unsuccessful though.

The authors recorded the data extracted from the randomized controlled studies in standardized forms, including: method used, number of participants, inclusion and exclusion criteria, age, country where the study was developed, description of interventions of control and intervention groups, continuous and dichotomous variables and references of the studies. In addition, a scale of quality registered in each form was applied. Disagreements were resolved through consensus meetings.

\section{METHODOLOGICAL QUALITY}

The validation of randomized controlled trials was done independently by two authors (CAJAIBA, L. S.; REIS, M. R.) using the Quality Scale ${ }^{7}$ and disagreements resolved at a consensus meeting. Criteria for the quality scale evaluation used in this research were: randomization, double-blind masking and set of losses and exclusions.

For randomization: the random sequence generation method was considered appropriate when it allowed each study participant to have the same chance of receiving each intervention and when the investiga- 
tor could not predict what the next treatment would be. For double-blind masking: studies were considered double-blind when the double-blind expression was used. The method was considered appropriate when neither the patient nor the data collector were able to identify the type of treatment given to each one or, in the absence of this statement, whether the use of identical placebos or imitations was mentioned. For losses and exclusions: participants who entered the study but did not complete the observation period or who were not included in the analysis and were described by the authors of the original articles. The number and reasons for losses in each group have to be stated. When there are no losses, this should also be stated in the article. When there was no description of losses, zero was assigned to this item.

Maximum of five points could be obtained through this scale, where: one point for each yes, one additional point for an appropriate method of randomization and one additional point for an appropriate method of masking. When the double-blind term was not mentioned but there was a description of the masking of the patient and the researcher of the variables, there was a score on this item in the quality scale. A study was considered of poor quality when it received two points or less in the quality scale.

\section{Variables}

Primary variables were mortality, quality of life and degree of satisfaction. Secondary variables include the need for postoperative analgesia, complications in anesthetic recovery room, length of hospital stay, length of stay in post-anesthesia care unit, length of ICU stay, surgical wound infection, other infection sites and blood transfusion.

\section{Data analysis}

Statistical analysis was performed with data from the original articles included and referring to the variables of interest to this systematic review. Statistical analysis was performed using the RevMan 5.1 software. ${ }^{8}$ For dichotomous variables, the relative risk (RR) and the 95\% confidence interval (95\% CI) were calculated using the Random Effect Model(REM); and for continuous variables, mean and standard deviation were used to generate mean difference (MD) and 95\% confidence interval using REM.

Statistical heterogeneity was quantified by means of the $\mathrm{I}^{2}$ test. When the $\mathrm{I}^{2}$ test values were greater than $50 \%$, results were considered heterogeneous.

\section{Analysis of sensitivity and homogeneity}

Sensitivity analysis was performed comparing the studies results with good and poor methodological quality. The heterogeneity research was performed by means of successive meta-analyses, with one study being withdrawn at a time until identification of the heterogeneity source. The research was performed in the meta-analyses that presented $\mathrm{I}^{2}$ test greater than $50 \%$.

\section{RESULTS}

\section{Selection of studies}

A flowchart demonstrating the selection process of articles relevant to this systematic review is shown in Figure 1. 2,189 titles were analyzed after applying the research strategy, of which 13 were identified as relevant in the process. ${ }^{9-21}$ Four of these were later excluded. ${ }^{18-21}$ Reasons that led to the exclusion are set out in Figure 1. Nine articles were identified as potential to answer the research question. ${ }^{9-17} 224$ references from these nine selected papers were also analyzed but no study was added because they did not respond to the research question or had already been included. In total, 2,413 titles and abstracts were screened.

FIGURE 1. FLOWCHART DEMONSTRATING PROCESS OF SELECTION OF STUDIES

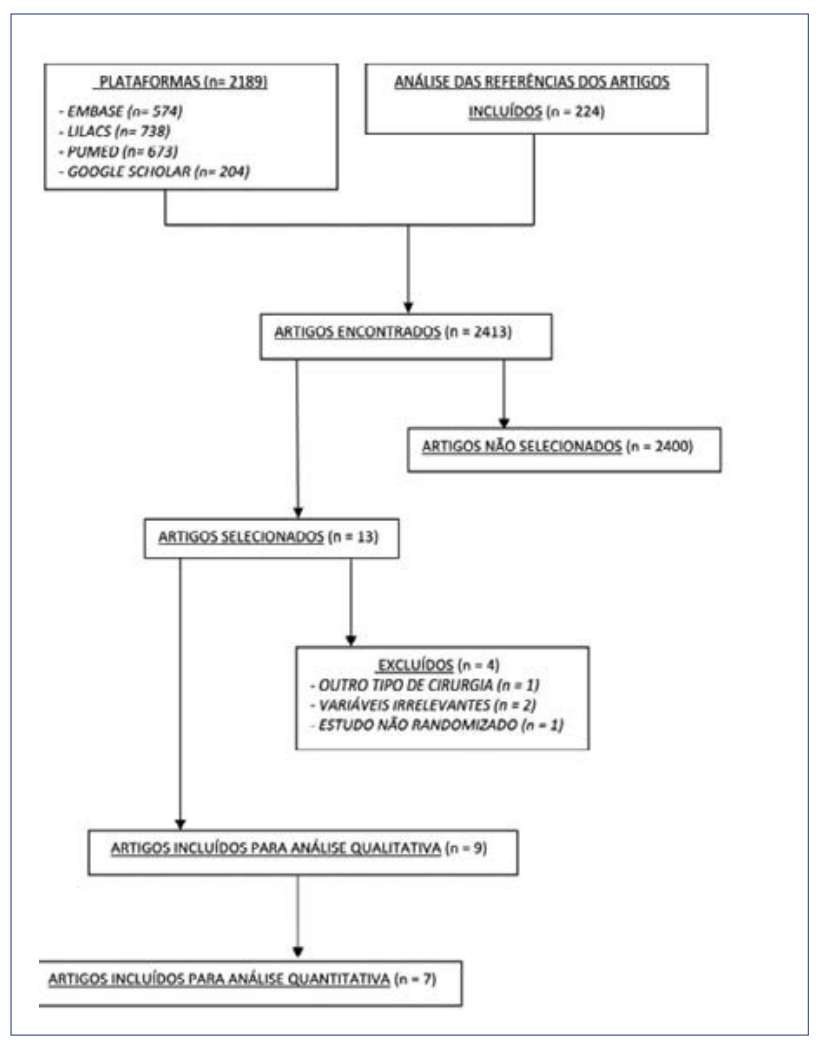




\section{QUALITY OF STUDIES}

Quality analysis of the randomized controlled trials selected for this systematic review showed that: seven articles received three points by the applied quality scale $^{9-13,15,16}$, one article received two points ${ }^{14}$ and another article ${ }^{17}$ only one point. One study has not had the method of randomization described. ${ }^{17}$ Six studies have not mentioned double-blind masking. ${ }^{10,}$ 12-14, 16, 17 Three studies justified the impossibility of performing double-blind masking. ${ }^{9,11,15}$ The quality score and main characteristics of the studies are presented in Table 1.

TABLE 1. MAIN CHARACTERISTICS OF STUDIES SELECTED

\begin{tabular}{|c|c|c|c|c|c|c|}
\hline $\begin{array}{l}\text { Authors } \\
\text { (Year of publi- } \\
\text { cation) }\end{array}$ & $\begin{array}{l}\text { Type of } \\
\text { anesthe- } \\
\text { sia }\end{array}$ & $\mathrm{N}$ & $\begin{array}{l}\text { Type of sur- } \\
\text { gery }\end{array}$ & Main results & $\begin{array}{l}\text { Quality } \\
\text { score }\end{array}$ & Comments \\
\hline \multirow{2}{*}{$\begin{array}{l}\text { Purwar et al. }{ }^{9} \\
(2015)\end{array}$} & AN & 31 & \multirow{2}{*}{$\begin{array}{l}\text { Vaginal surgery: } \\
\text { Vaginal pro- } \\
\text { lapse; } \\
\text { Urinary incon- } \\
\text { tinence }\end{array}$} & \multirow{2}{*}{$\begin{array}{l}\text { - There was no statistically significant } \\
\text { difference between groups regarding } \\
\text { nausea, quality of life, as well as dura- } \\
\text { tion of PACU, need for postoperative } \\
\text { analgesia and length of hospital stay. }\end{array}$} & \multirow[t]{2}{*}{3} & \multirow{2}{*}{$\begin{array}{l}\text { - Follow-up time: February } 2012 \\
\text { to May } 2013 . \\
\text { - NA pharmaceuticals: Hyperbaric } \\
\text { bupivacaine and fentanyl. }\end{array}$} \\
\hline & $A G$ & 29 & & & & \\
\hline \multirow{2}{*}{$\begin{array}{l}\text { Segal et al. }{ }^{\mathbf{1 0}} \\
(2014)\end{array}$} & $A N+A G$ & 20 & \multirow{2}{*}{$\begin{array}{l}\text { Robotic sacro- } \\
\text { colpopexy: } \\
\text { Vaginal pro- } \\
\text { lapse }\end{array}$} & \multirow[b]{2}{*}{$\begin{array}{l}\text { - Need for analgesia in percentage in } \\
\text { the NA + GA group was } 33 \% \text { and in the } \\
\text { GA group was } 53 \%(P<0.042) \text {. } \\
\text { - Average satisfaction level was } 9.8 \pm \\
0.5 \text { in the NA + GA group and } 8.7 \pm 1.5 \\
\text { in the GA group ( } P<0.014) \text {. } \\
\text { - The median in relation to the length } \\
\text { of hospital stay was equal in both } \\
\text { groups: two days. }\end{array}$} & \multirow[t]{2}{*}{3} & \multirow[b]{2}{*}{$\begin{array}{l}\text { Use of analgesics in the first } 24 \\
\text { hours after surgery was lower in } \\
\text { the NA group. } \\
\text { - Follow-up time: August } 2011 \text { to } \\
\text { September } 2012 \text {. } \\
\text { - NA + GA pharmaceuticals: } \\
\text { Fentanyl and morphine. }\end{array}$} \\
\hline & $A G$ & 20 & & & & \\
\hline \multirow{2}{*}{$\begin{array}{l}\text { Castro-Alves } \\
\text { et al. }{ }^{11} \\
(2011)\end{array}$} & AN & 35 & \multirow{2}{*}{$\begin{array}{l}\text { Abdominal } \\
\text { hysterectomy } \\
\text { (Benign dis- } \\
\text { eases) }\end{array}$} & \multirow[b]{2}{*}{$\begin{array}{l}\text { - The median difference in the overall } \\
\text { QoR-40 score in } 24 \text { hours between } \\
\text { NA e GA groups was } 17 \text { ( } 11 \text { to } 21.5 \text { ) ( } p \\
<0.001 \text { ). } \\
\text { - Patients in the NA group had better } \\
\text { scores on recovery quality ( } P<0.005 \text { ). } \\
\text { - There was a linear inverse rela- } \\
\text { tionship between opioid intake and } \\
\text { operative recovery quality in } 24 \text { hours, } \\
r^{2}=0.67 \text { ( } p<0.0001,95 \% \mathrm{Cl} \text { of } 0.77 \\
\text { to } 0.51 \text { ) and in } 48 \text { hours, } r^{2}=0.58 \text { ( } p< \\
0.0001,95 \% \mathrm{Cl} \text { of } 0.72 \text { to } 0.42 \text { ). } \\
\text { - The median for nausea in the first } 24 \\
\text { hours was } 11 \text { in the GA group and } 4 \text { in } \\
\text { the NA group ( } P=0.03 \text { ). }\end{array}$} & \multirow[t]{2}{*}{3} & \multirow[b]{2}{*}{$\begin{array}{l}\text { NA provides better recovery qual- } \\
\text { ity than GA. Opioid-sparing effects } \\
\text { in NA were associated with better } \\
\text { recovery quality. In the absence of } \\
\text { contraindications, neuraxial anes- } \\
\text { thesia seems to be an anesthetic } \\
\text { plan for these patients. } \\
\text { - Follow-up time: September } \\
2010 \text { to March } 2011 \text {. } \\
\text { - NA pharmaceuticals: Hyperbaric } \\
\text { bupivacaine and morphine. }\end{array}$} \\
\hline & $A G$ & 35 & & & & \\
\hline \multirow{2}{*}{$\begin{array}{l}\text { Wodlin et al. }{ }^{12} \\
\text { (2011) }\end{array}$} & AN & 91 & \multirow{2}{*}{$\begin{array}{l}\text { Abdominal } \\
\text { hysterectomy } \\
\text { (Benign dis- } \\
\text { eases) }\end{array}$} & \multirow{2}{*}{$\begin{array}{l}\text { - Neuraxial anesthesia reduced the } \\
\text { need for postoperative opioids. } \\
\text { - Episodes of vomiting were reported } \\
\text { mostly during the first day in the NA } \\
\text { group. }\end{array}$} & 3 & \multirow[b]{2}{*}{$\begin{array}{l}\text { NA with intrathecal morphine has } \\
\text { advantages over postoperative } \\
\text { symptoms and recovery after } \\
\text { abdominal hysterectomy. } \\
\text { - Follow-up time: March } 2007 \text { to } \\
\text { June } 2009 \text {. } \\
\text { - NA pharmaceuticals: Hyperbaric } \\
\text { bupivacaine and morphine. }\end{array}$} \\
\hline & $A G$ & 89 & & & & \\
\hline \multirow{2}{*}{$\begin{array}{l}\text { Wodlin et al. }{ }^{13} \\
\text { (2011) }\end{array}$} & AN & 91 & \multirow{2}{*}{$\begin{array}{l}\text { Abdominal } \\
\text { hysterectomy } \\
\text { (Benign dis- } \\
\text { eases) }\end{array}$} & \multirow{2}{*}{$\begin{array}{l}\text { - Medians related to the length of } \\
\text { hospital stay were, in the NA and GA } \\
\text { groups, } 46 \text { and } 50 \text { hours (P = 0.4004), } \\
\text { respectively. } \\
\text { - NA was associated with lower opioid } \\
\text { use and higher prevalence of vomiting. }\end{array}$} & \multirow[t]{2}{*}{3} & \multirow[b]{2}{*}{$\begin{array}{l}\text { Length of hospital stay was }<50 \\
\text { hours, regardless of the type of } \\
\text { anesthesia. NA reduced the need } \\
\text { for analgesia when compared to } \\
\text { GA. } \\
\text { - Follow-up time: March } 2007 \text { to } \\
\text { June } 2009 \text {. } \\
\text { - NA pharmaceuticals: Hyperbaric } \\
\text { bupivacaine and morphine. }\end{array}$} \\
\hline & $A G$ & 89 & & & & \\
\hline \multirow{2}{*}{$\begin{array}{l}\text { Massicotte et } \\
\text { al. }{ }^{14} \\
(2009)\end{array}$} & AN & 20 & \multirow{2}{*}{$\begin{array}{l}\text { Abdominal } \\
\text { hysterectomy }\end{array}$} & \multirow[b]{2}{*}{$\begin{array}{l}\text { - Morphine intake in the NA and GA } \\
\text { groups at } 48 \mathrm{~h} \text { was } 19 \pm 16 \text { and } 81 \pm 31 \\
\text { mg }(p<0.0001) \text {, respectively. } \\
\text { - Nausea at the } 6 \text { th hour in the GA } \\
\text { group had a median of } 1 \text {. } \\
\text { - Times in PACU in the NA and GA } \\
\text { groups were } 52 \pm 9 \text { and } 73 \pm 11 \text { minutes } \\
(P<0.0001) \text {, respectively. } \\
\text { - Hospital stay time was } 2.2 \pm 0.4 \text { and } \\
3.3 \pm 0.7 \text { days }(P=0.01) \text {. }\end{array}$} & \multirow[t]{2}{*}{2} & \multirow[b]{2}{*}{$\begin{array}{l}\text { Intrathecal morphine } 0.15 \text { mg with } \\
15 \mu g \text { fentanyl reduced postoper- } \\
\text { ative pain and morphine intake in } \\
\text { patients with controlled analge- } \\
\text { sia without increase of adverse } \\
\text { reactions in women submitted to } \\
\text { abdominal hysterectomy. } \\
\text { - Follow-up time: not described. } \\
\text { - NA pharmaceuticals: Hyper- } \\
\text { baric bupivacaine, fentanyl and } \\
\text { morphine. }\end{array}$} \\
\hline & $A G$ & 20 & & & & \\
\hline
\end{tabular}




\begin{tabular}{|c|c|c|c|c|c|c|}
\hline $\begin{array}{l}\text { Authors } \\
\text { (Year of publi- } \\
\text { cation) }\end{array}$ & $\begin{array}{l}\text { Type of } \\
\text { anesthe- } \\
\text { sia }\end{array}$ & $N$ & $\begin{array}{l}\text { Type of sur- } \\
\text { gery }\end{array}$ & Main results & $\begin{array}{l}\text { Quality } \\
\text { score }\end{array}$ & Comments \\
\hline \multirow{2}{*}{$\begin{array}{l}\text { Sprung et al. } .^{15} \\
(2006)\end{array}$} & AN & 45 & \multirow{2}{*}{$\begin{array}{l}\text { Vaginal hyster- } \\
\text { ectomy }\end{array}$} & \multirow[b]{2}{*}{$\begin{array}{l}\text { - Morphine intake (mg) in the PACU } \\
\text { in the NA and GA groups was } 1.0 \pm 3.0 \\
\text { and } 9.0 \pm 7.3(P<0.001) \text {, respectively. } \\
\text { - Morphine intake }(\mathrm{mg}) \text { in the first } 12 \\
\text { hours after discharge from the PACU } \\
\text { was } 7.9 \pm 8.3 \text { and } 14.8 \pm 11.2(P<0.001) \text {, } \\
\text { respectively. } \\
\text { - Frequency of nausea in the PACU } \\
\text { was lower in the NA group than in the } \\
\text { GA group }(P=0.021) \text {. } \\
- \text { In } 2 \text { weeks of follow-up, } 69 \% \text { of the } \\
\text { NA patients and } 48 \% \text { of the GA group } \\
\text { were painless ( } P=0.044) \text {. }\end{array}$} & \multirow[t]{2}{*}{3} & \multirow[b]{2}{*}{$\begin{array}{l}\text { There was no significant difference } \\
\text { in the length of patients' hospital } \\
\text { stay or postoperative functional } \\
\text { status between the two groups. } \\
\text { - Follow-up time: April } 2001 \text { to } \\
\text { February } 2005 \text {. } \\
\text { - NA pharmaceuticals: Hyper- } \\
\text { baric bupivacaine, clonidine and } \\
\text { morphine. }\end{array}$} \\
\hline & $A G$ & 44 & & & & \\
\hline \multirow{2}{*}{$\begin{array}{l}\text { Kuramochi et } \\
\text { al. }{ }^{6} \\
(2004)\end{array}$} & AN & 14 & \multirow{2}{*}{$\begin{array}{l}\text { Laparoscopic } \\
\text { surgery for } \\
\text { infertility treat- } \\
\text { ment }\end{array}$} & \multirow{2}{*}{$\begin{array}{l}\text { - Mean hospital stay time was } 1 \text { day in } \\
\text { both NA and GA groups. }\end{array}$} & \multirow[t]{2}{*}{3} & \multirow[b]{2}{*}{$\begin{array}{l}\text { NA, when used in laparoscopic } \\
\text { surgery for infertility treatment, } \\
\text { has advantages over GA in terms } \\
\text { of analgesic effects, postoperative } \\
\text { respiratory function and return to } \\
\text { daily preoperative activities. } \\
\text { - Follow-up time: not described. } \\
\text { - NA pharmaceuticals: Mepiva- } \\
\text { caine and fentanyl. }\end{array}$} \\
\hline & $A G$ & 9 & & & & \\
\hline \multirow{2}{*}{$\begin{array}{l}\text { Vofsi et al. }{ }^{\mathbf{1 7}} \\
(2004)\end{array}$} & AN & 8 & \multirow{2}{*}{$\begin{array}{l}\text { Gasless lapa- } \\
\text { roscopy }\end{array}$} & \multirow{2}{*}{$\begin{array}{l}\text { - Significant differences were not de- } \\
\text { tected between the groups during the } \\
\text { operative and postoperative periods, } \\
\text { except for lower need for analgesics in } \\
\text { the AN anesthetic recovery unit. }\end{array}$} & \multirow[t]{2}{*}{1} & \multirow{2}{*}{$\begin{array}{l}\text { - Follow-up time: not described. } \\
\text { - Pharmaceuticals used: Bupiva- } \\
\text { caine and fentanyl. }\end{array}$} \\
\hline & $A G$ & 8 & & & & \\
\hline
\end{tabular}

NA = neuraxial anesthesia; GA = general anesthesia; $N$ = number of participants; $P A C U$ = post-anesthesia care unit.

\section{VARIABLES}

Analysis of the studies allowed us to perform meta-analyses of the following variables: nausea and vomiting, need for postoperative analgesia, length of hospital stay and time in post-anesthesia care unit. Meta-analysis was not possible for the following variables: mortality, quality of life, degree of satisfaction, length of ICU stay, surgical wound infection, other infection sites and blood transfusion. The reasons are described below.

Mortality: One study has mentioned mortality. ${ }^{15}$ The authors reported that there were no cases of death and it was not possible to perform statistical analysis of this variable. Only with one study it is not possible to perform a meta-analysis.

Quality of life: Two studies presented this variable. ${ }^{9} 15$ Two scales were used. In both studies, the SF-36 questionnaire was applied and in one of them ${ }^{9}$ was also used the International Consultation on Incontinence Questionnaire on Vaginal Symptoms (ICIQVS). As only one used ICIQ-VS, meta-analysis is not feasible, since at least two studies are necessary to perform it. The number of patients who presented satisfactory quality of life in articles using SF36 was not identified.
Degree of satisfaction: Two studies presented this variable. ${ }^{10,15}$ In these, different units of measure were used. In one, a verbal scale of 0 to 10 was used..$^{10}$ In another, the scale was classified as Very Satisfactory, Satisfactory, Somewhat Satisfactory and Unsatisfactory in relation to anesthesia and post-procedure analgesia. ${ }^{15}$

Length of ICU stay: No studies were found with this variable. However, one study reported that two people needed ICU admission, one in the NA group, representing $1.2 \%$, and another in the GA group, representing $1.3 \%{ }^{13}$ And another states that there was no admission to ICUs. ${ }^{15}$

Blood transfusion: In only one study, this variable was addressed..$^{13}$ How many patients needed blood transfusion was mentioned. In patients submitted to GA, three of them had blood transfusion, which represented $3.8 \%$ of these individuals. Of those submitted to NA, no patients needed it. Only with one study it is not possible to perform a meta-analysis.

Infection of operative wound and infection in other sites: No studies were found with these variables.

Nausea and vomiting: This variable was analyzed in six studies., ${ }^{91-15}$ Meta-analysis was only possible with two. ${ }^{11,13}$ No significant statistical difference was 
found among studies (RR = 1.48; 95\% CI: 0.49 to 4.48; $\mathrm{P}=0.48$; two studies; 230 participants). Of the four articles in which it was not possible to perform the meta-analysis ${ }^{9}, 12,14,15$, the first one presented the number of people who needed treatment for nausea, being for the NA group 32 people, representing $71 \%$ and for the GA group 30 people (68\%). ${ }^{15}$ The second one presented the number of people in the median who evolved with nausea at different times in hours after the procedure $(6 \mathrm{~h}, 12 \mathrm{~h}, 18 \mathrm{~h}, 24 \mathrm{~h}, 48 \mathrm{~h})$, obtaining a non-zero result only at the first moment (6h) for the GA group, equal to $1{ }^{15}$ The third one presented the number of people who evolved with nausea from a four-level verbal scale (without nausea, mild, moderate, severe) at different times. ${ }^{9}$ And the fourth one presented the number of vomiting situations in days (day 0 , day 1 and day 2 ) in the different groups. ${ }^{12}$ It was observed that there was significant statistical heterogeneity $\left(\mathrm{I}^{2}=65 \% ; \mathrm{X}^{2}=2.86 ; \mathrm{P}=0.09\right)$. It was not possible to identify the source of the heterogeneity since meta-analysis is only possible with at least two articles.

Need for postoperative analgesia: Five studies have analyzed this variable. ${ }^{10,}$ 13-15, 17 Meta-analysis was possible with two of them. ${ }^{10,17}$ There was no statistically significant difference in the analysis $(\mathrm{RR}=$ 0.76; 95\% CI: 0.11 to 5.12; $\mathrm{P}=0.78$; two studies; 54 participants). Of the three studies that did not participate in the meta-analysis, two presented mean in milligrams of the amount of analgesic drugs ${ }^{14,15}$ and one presented this data in median ${ }^{13}$. It was observed that there was significant statistical heterogeneity $\left(\mathrm{I}^{2}\right.$ $\left.=88 \% ; \mathrm{X}^{2}=8.19 ; \mathrm{P}=0.004\right)$, and, therefore, it was not possible to identify the source of heterogeneity.

Length of hospital stay: This variable was analyzed in five studies. ${ }^{9}$, 10, 14-16 Meta-analysis was possible with two studies. ${ }^{14,15}$ There was no statistically significant difference (MD $=-0.50 ; 95 \% \mathrm{CI}:-1.67$ to 0.68; $\mathrm{P}=0.41$; two studies; 129 participants). Of the three articles in which it was not possible to perform the meta-analysis, the first one presented the variable in median, being for the NA + GA group equal to 2 and for the GA group equal to $2 .^{10}$ The second one presented the mean in hours, being for the NA group $36.4 \pm 36.7$ and for the GA group $52.6 \pm 53.2 .^{9}$ The third one presented the average in days, being for the NA and GA groups equal to 1 . Nevertheless, the standard deviation was not informed. ${ }^{16}$ It was observed that there was significant statistical heterogeneity $\left(\mathrm{I}^{2}\right.$ $\left.=96 \% ; X^{2}=26.16 ; P=0.00001\right)$. It was not possible to identify the source of heterogeneity.

Time in a post-anesthesia care unit: Five studies analyzed this variable. ${ }^{9,13-15,17}$ It was possible to perform meta-analysis with four of them., 14, 15, 17 There was no statistically significant difference $(\mathrm{MD}=-4.81$; 95\% CI: -24.02 to 14.39; P = 0.62; four studies; 205 participants), as shown in Figure 2. In the study in which it was not possible to perform meta-analysis, the variable was analyzed as median hours and for the NA group it was 3.6 and for the GA group, 4.3. ${ }^{13}$ It was observed that there was statistical heterogeneity $\left(I^{2}=78 \% ; X^{2}=13.55 ; P=0.004\right)$. The heterogeneity test was performed by withdrawing each study successively. One study was identified as a source of heterogeneity. ${ }^{14}$ Analysis without this study did not result in a statistically significant difference $(\mathrm{MD}=$ 5.17; $95 \%$ CI: -8.16 to 18.50 ; $\mathrm{P}=0.45$; three studies; 165 participants).

Included in the figure below:

Massicotte et al. ${ }^{14}, 2009$

Purwar et al. ${ }^{9}, 2015$

Sprung et al. ${ }^{15}, 2006$

Vofsi et al. ${ }^{17}, 2014$

FIGURE 2. FOREST PLOT OF VARIABLE TIME IN POST-ANESTHESIA CARE UNIT.

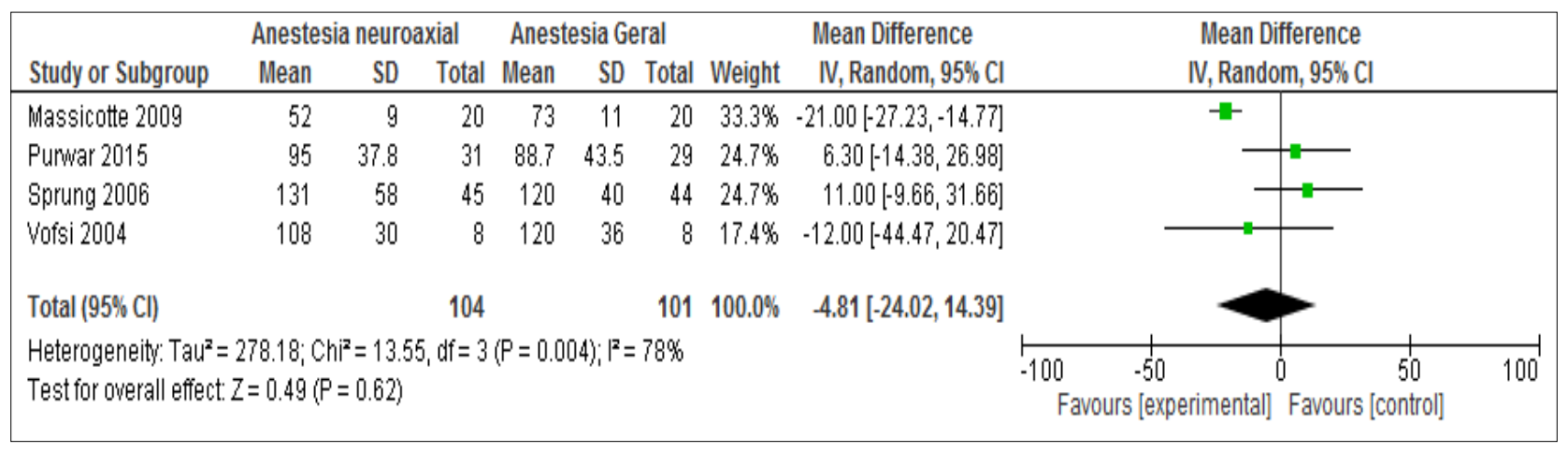




\section{DISCUSSION}

Although some studies point to NA as a good option for postoperative pain control, the impact of this technique on mortality and surgical morbidity is not yet evident. ${ }^{22}$ This systematic review was unable to prove greater effectiveness and safety of neuraxial anesthesia compared to general anesthesia for major gynecologic surgeries, since primary variables were not addressed by most of the studies selected.

Some limitations were identified in this systematic review. There were discrepancies in the units of measure and scales presented for variables quality of life, satisfaction, need for postoperative analgesia, length of hospital stay and nausea and vomiting, which made it difficult to perform the meta-analyses. In some cases, contact with the authors was attempted but no answers were obtained. Statistical heterogeneity was identified in the analyses. Exploration was carried out to find the source of this heterogeneity. However, some variables were analyzed with only two articles and results were kept in the text for readers' appreciation.

Variables nausea and vomiting, need for analgesia, length of hospital stay and time in the post-anesthesia care unit were not statistically significant. The small number of events in the studies and a small number of participants identified with these variables may have been some of the limiting factors for analysis.

RR in nausea and vomiting was 1.48 , demonstrating that there was no difference between the groups. A systematic review in 2005 evaluated that the GA group had more episodes of nausea than the NA group. ${ }^{23}$ Another study reported the lower incidence of postoperative nausea and vomiting in subjects submitted to NA. ${ }^{24}$ The two articles used for meta-analysis presented clinical heterogeneity that justified the absence of statistical significance, such as the number of discrepant samples between them. ${ }^{11,13}$

$\mathrm{RR}$ in need of analgesia was 0.76 , demonstrating that there was no difference between the groups. The studies used for meta-analysis showed clinical heterogeneity that may have influenced the analysis, such as different surgical techniques, anesthetic ap$\operatorname{proach}^{10,17}$ and a higher mean age in one of the studies $^{\mathbf{1 7}}$. There was discrepancy in the presentation of the data among the articles of meta-analysis and the others $^{\mathbf{1 4}, 15}$ that addressed this variable.

The mean difference in hospital stay time was -0.50 , demonstrating that there was no significant statistical difference between the groups. A systematic review of 2016 found that the use of NA significantly reduces length of hospital stay. ${ }^{25}$ The studies used in the meta-analysis ${ }^{14,15}$ showed clinical heterogeneity that may have influenced the analysis, such as different surgical techniques, mean age in one of the studies ${ }^{15}$, drugs used in the anesthetic approach and number of samples. In both articles, the authors found that there was no significant difference between the NA and GA groups.

The mean difference in post-anesthesia care unit was -4.81 , demonstrating that there was no significant statistical difference between the groups. The studies used for meta-analysis showed clinical heterogeneity that may have influenced the analysis, such as types of surgical techniques, mean age of patients, drugs used in anesthetic approach and sample size. ${ }^{9,14,15,17}$

The mortality variable did not generate meta-analysis. However, the only primary study showed that no cases of death were recorded during the research. ${ }^{15}$ It is not the authors' consensus to evaluate this variable. A systematic review in 2000 showed that neuraxial anesthesia reduces mortality and other types of severe postoperative complications. ${ }^{1}$ Another systematic review conducted in 2016 found that the association of NA with GA, when compared to the use of GA, does not have a significant difference in mortality. ${ }^{26}$

The blood transfusion variable ${ }^{13}$ has not generated meta-analysis either. However, the only primary study demonstrated that $3.8 \%$ of patients in the GA group required transfusion and $0 \%$ in the NA group. It is noted that it is not the authors' priority to analyze this variable.

The quality of life variable, reported in two studies, was expressed in two different scales and in both studies there was no significant statistical difference between the groups. ${ }^{9,15}$ SF-36 is a multidimensional questionnaire that seeks a generic measure of health status consisting of 36 items inserted in eight domains (functional capacity, physical aspects, pain, general health, vitality, social aspects, emotional aspects and mental health). ${ }^{27}$ ICIQ-VS is a module of the ICIQ which consists of a comprehensive assessment of severity and impact of vaginal symptoms and related sexual issues, particularly those attributed to pelvic organ prolapse, in order to characterize the severity of these symptoms to measure their impact and evaluate the treatment 
outcome. ${ }^{28}$ As the studies analyzed the same variable, however in a different way and with different questionnaires, it is impossible to carry out a meta-analysis for comparative effect.

The degree of satisfaction variable, reported in two studies, was expressed in different scales for evaluation, and in both there was no significant statistical difference between the groups in relation to satisfaction in pain management. ${ }^{10,15}$ As the studies analyzed the same variable, but in a different way and with different questionnaires, it is impossible to carry out meta-analysis for comparative effect.

It is necessary to carry out more randomized controlled trials of good quality and with greater number of participants so that the influence of anesthetic techniques on the variables proposed in this review can be analyzed and, in this way, to guide conducts in the medical area. Based on assumptions of $5 \%$ mortality in the general anesthesia group, $1 \%$ mortality in the neuraxial anesthesia group, $80 \%$ power and $5 \%$ level of significance, 284 participants shall be re- quired in each group for future studies in order to answer this research question.

In light of these results, suggestions for future research can be offered. Analysis of mortality, quality of life, degree of satisfaction, complications in the post-anesthesia care unit, length of ICU stay, surgical and other wound infection and blood transfusion are proposed so that it is possible to evaluate the impact of different anesthetic techniques in gynecologic surgeries.

This systematic review has not presented definitive results. Therefore, previous training and daily practical experience over the years shall allow professionals to choose the most effective and safe technique to be employed.

\section{CONCLUSION}

To date, evidence assessed from the studies included is insufficient to ensure that neuraxial anesthesia has greater effectiveness and safety compared to general anesthesia for major gynecologic surgeries.

\section{REFERENCES}

1. Rodgers A, Walker N, Schug S, McKee A, Kehlet H, van Zundert A, et al. Reduction of postoperative mortality and morbidity with epidural or spinal anaesthesia: results from overview of randomised trials. BM]. 2000;321(7275):1493

2. Braz LG, Braz DG, Cruz DS, Fernandes LA, Módolo NS, Braz JR. Mortality in anesthesia: a systematic review. Clinics (Sao Paulo). 2009;64(10):9991006.

3. Afolabi BB, Lesi FE. Regional versus general anaesthesia for caesarean section. Cochrane Database Syst Rev. 2012;10:CD004350.

4. Bajwa SJ, Kulshrestha A. Anaesthesia for laparoscopic surgery: general vs regional anaesthesia. J Minim Access Surg. 2016;12(1):4-9.

5. Higgins JPT, Green S. Cochrane handbook for systematic reviews of interventions. Version 5.0.2. The Cochrane Collaboration; 2011. [cited 2017 Mar 5] Available from: www.cochrane-handbook.org.

6. Moher D, Liberati A, Tetzlaff J, Altman DG; PRISMA Group. Preferred reporting items for systematic reviews and meta-analyses: the PRISMA statement. PLoS Med. 2009;6(7):e1000097.

7. Jadad AR, Moore RA, Carroll D, Jenkinson C, Reynold DJ, Gavaghan DJ, et al. Assessing the quality of reports of randomized clinical trials: is blinding necessary? Control Clin Trials. 1996;17(1):1-12.

8. Review Manager (RevMan) [Computer program]. Version 5.1. Copenhagen: The Nordic Cochrane Centre, The Cochrane Collaboration, 2011. [cited 2017 Mar 5] Available from: http://ims.cochrane.org/ revman/.

9. Purwar B, Ismail KM, Turner N, Farrel A, Verzune M, Annappa M, et al. General or spinal anaesthetic for vaginal surgery in pelvic floor disorders (GOSSIP): a feasibility randomised controlled trial. Int Urogynecol ). 2015;26(8):1171-8.
10. Segal D, Awad N, Nasir H, Mustafa S, Lowenstein L. Combined spinal and general anesthesia vs general anesthesia for robotic sacrocervicopexy: a randomized controlled trial. Int Urogynecol J. 2014;25(3):369-74.

11. Castro-Alves LJ, Azevedo VL, Braga TF, Gonçalves AC, Oliveira GS Jr. The effect of neuroaxial versus general anesthesia techniques on postoperative quality of recovery and analgesia after abdominal hysterectomy: a prospective, randomized, controlled trial. Anesth Analg. 2011;113(6):1480-6.

12. Wodlin NB, Nilsson L, Arestedt K, Kjolhede P; 'GASPI' Study Group. Mode of anesthesia and postoperative symptoms following abdominal hysterectomy in fast-track setting. Acta Obstet Gynecol Scand. 2011;90(4):369-79.

13. Wodlin NB, Nilsson L, KjØlhede P; for the GASPI study group. The impact of mode of anesthesia on postoperative recovery from fast-track abdominal hysterectomy: a randomised clinical trial. BJOG. 2011; 118(3):299-308.

14. Massicotte L, Chalaoui KD, Beaulieu D, Roy JD, Bissonnette F. Comparison of spinal anesthesia with general anesthesia on morphine requirement after abdominal hysterectomy. Acta Anaesthesiol Scand. 2009;53(5):641-7.

15. Sprung J, Sanders MS, Warner ME, Gebhart JB, Stanhope CR, Jankowski C), et al. Pain relief and functional status after vaginal hysterectomy: intrathecal versus general anesthesia. Can J Anaesth. 2006;53(7):690-700.

16. Kuramochi K, Osuga $Y$, Yano T, Momoeda M, Fujiwara T, Tsutsumi O, et al. Usefulness of epidural anesthesia in gynecologic laparoscopic surgery for infertility in comparison to general anesthesia. Surg Endosc. 2004;18(5):847-51.

17. Vofsi O, Barak M, Moscovici R, Bustan M, Katz Y. Cardiorespiratory parameters during conventional or gasless gynecological laparoscopy under general or regional anesthesia. Med Sci Monit. 2004;10(4):CR152-5.

18. Danelli G, Berti M, Casati A, Albertin A, Deni F, Nobili F, et al. Spinal block 
or total intravenous anaesthesia with propofol and remifentanil for gynaecological outpatient procedures. Eur | Anaesthesiol. 2002;19(8):594-9.

19. Goldenberg M, Cohen SB, Etchin A, Mashiach S, Seidman DS. A randomized prospective comparative study of general versus epidural anesthesia for transcervical hysteroscopic endometrial resection. Am | Obstet Gynecol. 2001;184(3):273-6.

20. Dyer RA, Camden-Smith K, James MF. Epidural lidocaine with sufentanil and epinephrine for abdominal hysterectomy under general anaesthesia: respiratory depression and postoperative analgesia. Can | Anaesth. 1992;39(3):220-5.

21. Lin L, Liu C, Tan H, Ouyang H, Zhang Y, Zeng W. Anaesthetic technique may affect prognosis for ovarian serous adenocarcinoma: a retrospective analysis. Br J Anaesth. 2011;106(6):814-22.

22. França MA, Araújo SA, Abreu EMF, Jorge JC. Anestesia peridural: vantagens e desvantagens na prática anestésica atual. Rev Med Minas Gerais. 2015;25(Supl 4):S36-S47.

23. McLain RF, Kalfas I, Bell GR, Teztlaff JE, Yoon HJ, Rana M. Comparison of spinal and general anesthesia in lumbar laminectomy surgery: a case-controlled analysis of 400 patients. | Neurosurg Spine. 2005;2 (1):17-22.
24. Machaczka M, Kalaitzakis E, Eleborg L, Ljungman $P$, Hägglund H. Comparison of general vs regional anaesthesia for BM harvesting: a retrospective study of anaesthesia-related complications. Bone Marrow Transplant. 2010;45(1):53-61.

25. Johnson RL, Kopp SL, Burkle CM, Duncan CM, Jacob AK, Erwin PJ. Neuraxial vs general anaesthesia for total hip and total knee arthroplasty: a systematic review of comparative-effectiveness research. $\mathrm{Br}$ | Anaesth. 2016;116(2):163-76.

26. Barbosa FT, Cunha RM, Ramos FWS, Lima FI, Rodrigues AK, Galvão $A M N$, et al. Effectiveness of combined regional-general anesthesia for reducing mortality in coronary artery bypass: meta-analysis. Braz | Anesthesiol. 2016:66(2):183-93.

27. Ware JE Jr, Gandek B. Overview of the SF-36 Health Survey and the International Quality of Life Assessment (IQOLA) Project. J Clin Epidemiol. 1988;51(11):903-12.

28. Price N, Jackson SR, Avery K, Brookes ST, Abrams P. Development and psychometric evaluation of the ICIQ Vaginal Symptoms Questionnaire: the ICIQ-VS. B|OG. 2006;113(6):700-12. 